\title{
How Can the Empowerment of Employees with Intellectual Disabilities Be Supported?
}

\author{
Frauke Fuhrmann ${ }^{1}$ \\ Margit Scholl ${ }^{1}$ \\ Rainer Bruggemann ${ }^{2}$
}

\footnotetext{
${ }^{1}$ Technical University of Applied Sciences Wildau, Department of Business, Computing, Law, Hochschulring 1, 15745 Wildau, Germany, frauke.fuhrmann@th-wildau.de, +49 3375 508-574

${ }^{2}$ Leibniz-Institute of Freshwater Ecology and Inland Fisheries, Department of Ecohydrology Müggelseedamm 310, 12587 Berlin-Friedrichshagen, Germany
}

\begin{abstract}
The project "Barrier-Reduced Machines in Innovative Interaction" (iBaMs) was aimed at enabling employees with intellectual disabilities to extend their range of tasks and to increase their level of responsibility. This goal is to be achieved by an assistive accessible control panel for the operation of complex computer-controlled machines. Therefore, users' needs and skills as well as design requirements had to be specified in the project. The result is a concept for an assistive control panel whose display interface can be tailor-made to individual needs. Furthermore, indicators for characterizing user profiles and control panels were identified, and a concept was developed of how control panels can be determined and matched to the needs and preferences of individual employees. The complexity in recognizing the requirements of people with intellectual disabilities in a digital world is mapped onto a complex interaction of two sets of indicators-namely social indicators and technical indicators describing control panels. Guidelines on how the results can be evaluated are presented using plausible but fictitious data.
\end{abstract}

Keywords: intellectual disability, assistive control panel, matching, social indicators, technical indicators, complexity, user perspective, user experience, personalization

\section{Acknowledgments}

We wish to thank the Federal Ministry of Education and Research (BMBF) for funding the project. We would also like to thank the employees of CVJM-Sozialwerk Wesermarsch e. V. for their active involvement in the project. Furthermore, we thank the anonymous reviewers for their helpful critical comments. 


\section{Introduction}

People with intellectual disabilities experience structural discrimination: there are individual and specific institutional and cultural conditions in place that hinder them from participating autonomously in social life and developing and exercising their capacities to the full extent (Young 1990). Besides ethical and moral reasons for advancing the inclusion of people with intellectual disabilities, it is also an economic necessity to improve their labor participation and employment rate, as demographic changes are leading to a labor shortage. Hence, it is on one hand, a matter of quality of life, and, on the other hand, an urgent economic need.

In the context of quality of life, mathematical concepts arising from partial order theory are useful to describe and evaluate aspects such as poverty and economic well-being (Fattore 2008; Annoni et al. 2014). Partial order theory deals with comparisons driven by indicator values where each single indicator induces an order. The theory of partial order comes into play because there are many aspects that are relevant for the social inclusion of people with intellectual disabilities. Thus, the simultaneous action of many indicators is to be analyzed and multidimensional concepts are required to ensure economic and social equality.

Innovative assistive technologies could enable and empower employees with intellectual disabilities to perform more demanding and more responsible tasks in working life, for example, in operating complex computer-controlled machines, as well as giving them more autonomy in carrying out their roles. In this way, they could relieve specialized staff and increase the efficiency of the organization. Research findings regarding innovative technologies that support employees with intellectual disabilities could also benefit other target groups and also support their equal participation in social life. Assistive technology may be understood as "technologies, equipment, devices, apparatus, services, systems, processes and environmental modifications used by disabled and/or elderly people to overcome the social, infrastructural and other barriers to independence, full participation in society and carrying out activities safely and easily" (Hersh and Johnson 2008: 196). This definition corresponds to the understanding of disability expressed by the UN: "disability results from the interaction between people with impairments and attitudinal and environmental barriers that hinder their full and effective participation in society on an equal basis with others" (UN 2006: 5). Intellectual disability in turn is defined as "a disability characterized by significant limitations in both intellectual functioning and in adaptive behavior, which covers many everyday social and practical skills“ (American Association on Intellectual and Developmental Disabilities 2013). Unfortunately, research and projects that focus on innovative technologies to support and empower employees with intellectual disabilities in their working life are almost nonexistent. To change this, the project "Barrier-Reduced Machines in Innovative Interaction" (iBaMs), funded by the Federal Ministry of Education and Research (BMBF), was conducted as a pilot-project, exploring the scientific framework. The mathematical methodology, described below, is presented using fictitious albeit plausible data. 
In the long term, the aim of iBaMs is to enable or make it easier for employees with intellectual disabilities to operate complex computer-controlled machines and thus foster their participation in working life. Equal participation in working life is crucial for full social integration and acceptance, and consequently for health and well-being (Martins 2015). This long-term goal is to be attained by an assistive control panel that is accessible to employees with intellectual disabilities. Developers and designers of such a control panel need to understand and specify the intended users and what their needs, preferences, impairments, barriers they experience and working tasks are (Mazzone et al. 2010). Therefore, the main objective of the one-year project iBaMs was to explore the user perspective - skills, needs, impairments, and barriers — of employees with intellectual disabilities in handling digital technology. At the same time, business processes were investigated in order to identify potential for optimization and for enhancing the efficiency of sheltered workshops. These workshops offer people in need of rehabilitation vocational training, working sections, and day-care centers to enable them to participate autonomously in society and to enhance their integration in working life (BAG WfbM 2007). Though the main responsibility of sheltered workshops is to qualify and to advance the integration of people with impairments in working life, they have to compete successfully with their products and services on the market. This means that they face the challenge of only being able to accept orders that correspond to the abilities of their employees as well as keeping up with state-of-the-art technical standards, while still being competitive.

Based on the examination of the user perspective and the business processes, the design specifications for the assistive accessible control panel had to be determined. In order to assign suitable control panels to given user requirements, indicators characterizing both the control panels and users had to be identified. Finally, a concept was developed of how control panels can be matched to the requirements and preferences of individual employees which is a complex task needing detailed sociological and engineering knowledge. The one-year project iBaMs should be regarded as preparation for a more extensive research project in which a prototype of an assistive control panel can be developed and the mathematical machinery, described below, can be applied and validated.

The paper continues as follows: in section 2, a brief overview of current research projects is given, and, based on that, the iBaMs research questions are presented. In section 3, the methodological approach of iBaMs is introduced, and, in section 4, the main results of the project are discussed. Finally, in section 5, conclusions are drawn and in section 6, limitations of the research project are discussed in conjunction with highlighting further research activities.

\section{Research Background}

\subsection{Equality aspect}

The research on social indicators tries to give complex and abstract phenomena such as quality of life, well-being, poverty, etc. a structure and makes an effort to make them measureable for analyzing purposes (Annoni et al. 2011; Maggino 2014). People with (intellectual) disabilities face particular 
challenges to experience equality and the same standard of quality of life and well-being as people without disabilities (van Campen and van Santvoort 2013; Graham and Ross 2016). Therefore, the project iBaMs was aimed at improving their quality of life by enabling the enhancement of their capabilities and their social inclusion in working life through the development of an assistive accessible control panel. There are only a few studies in the field of social indicators that examine the participation of people with disabilities and thereby the equality they experience in working life (Boccuzzo and Fabbris 2012; Agovino and Parodi 2014; Boccuzzo and Maron 2014). However, these studies mostly focus on people with a high level of education. Therefore, the inclusion of people with intellectual disabilities in working life in the research field of social indicators and quality of life is to date a largely under-researched issue.

\subsection{Information and communication technology}

Research activities on innovative and assistive information and communication technology (ICT) that support employees with disabilities mainly focus on people with physical disabilities and therefore neglect the needs of people with intellectual disabilities. This one-sided concentration is also apparent in the report "Technologies in the Context of Disability Compensation at the Workplace" by the Office of Technology Assessment at the German Bundestag (TAB), which refers only to assistive technologies for people with physical disabilities (Revermann and Gerlinger 2009). One exception is a doctoral thesis that investigates how working with CNC (Computerized Numerical Control) technology, compared to conventional machinery, affects the personal development of people with intellectual disabilities. The main result of this empirical study is that ICT does not automatically enhance personal development, but that accompanying measures that consider the requirements and abilities of the employees are necessary (Kim 2004). There are also empirical studies that explore the use of ICT by people with disabilities: Irwin and Sesto (2012), for example, comparing touch characteristics of people with and without motor impairments in using touch-screen technology.

\subsection{Learning technologies}

Most of the research work on technological innovations for people with intellectual disabilities concentrates on the learning context. The corresponding papers present current developments of innovative assistive technologies: Mazzone et al. (2010), for example, report on three projects that develop technological learning support for learning activities in daily living, for training courses in a specific working context and throughout the person's professional development. Giannoulis et al. (2013) describe a multimedia education tool in the higher education context that both provides information on different media types and facilitates the exchange between students. Seale et al. (2015) analyze the use of technology in higher education by students with sensory, cognitive, physical, or psychological impairments to support their learning. Furthermore, there are research activities that develop frameworks and approaches to support the development and evaluation of accessible ICTbased learning technologies (e.g., Angkananon et al. 2014; Hersh 2014). 


\subsection{Our approach}

What is still missing, though, is a thorough exploration and understanding of how complex computercontrolled machines could be accessible and easily operable by employees with intellectual disabilities. To close this research gap, the project iBaMs addressed the following research questions:

1. What are the users' skills, needs, and requirements?

2. Which design elements best suit employee needs?

3. What (technological and pedagogical) support will optimize workflows and solve potential problems?

4. How can it be objectively determined which control panel is optimal for certain employees with their requirements and abilities?

The steps undertaken to answer the first three questions are presented in section 3.1. A separate section (section 3.2) is devoted to explain the methodological procedure to answer the fourth question.

\section{Methods}

\subsection{Requirement analysis}

\subsubsection{General procedure}

In order to answer the first three research questions, a participative research approach was chosen in which "the research process [is planned and conducted] with those people whose life-world and meaningful actions are under study" (Bergold and Thomas 2012: 1). The participative research approach aimed at determining the requirements for an assistive accessible control panel from the user perspective. The combination of the applied research methods, which are explained in more detail in table 2, was called requirement analysis (see figure 1). First, an assessment was made both of the needs and skills of employees with intellectual disabilities in using digital technology and of the requirements of the business processes involved. The design specifications were then determined based on these results.

Requirement Analysis

Participative Research Approach

Interviews
- Production and
factory super-
visors, team
leaders
- Employees

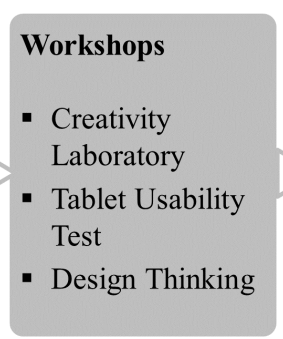

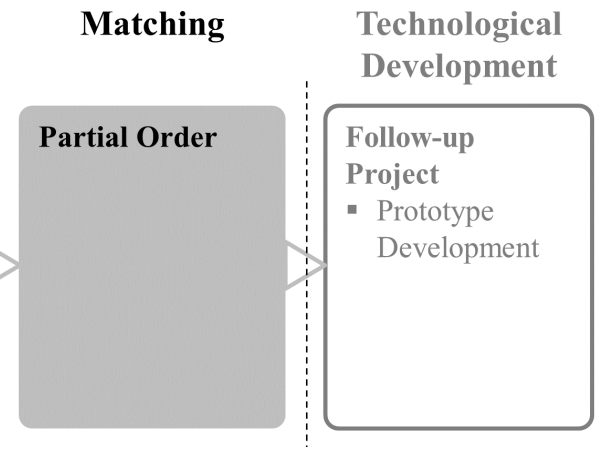

Fig 1 Methodological approach

The participation of potential users of the assistive control panel throughout the research process is essential for the development of a usable and accessible control panel (Mazzone et al. 2010), which should be developed in the more extensive follow-up project that is planned (see figure 1). As users of 
the control panel both employees with intellectual disabilities and specialized staff are considered. The latter are skilled employees without impairments who, for example, lead a shop-floor level within the sheltered workshops. Their remits are versatile: Training, motivating, and instructing employees with intellectual disabilities and taking care of their safety, setting up and controlling the machines as well as carrying out clerical tasks like customer support, procurement, and tender preparation. Specialized staff also fulfil other management functions such as supervising the whole production process.

To gather empirical data for the requirement analysis CVJM-Sozialwerk Wesermarsch e. V. (CVJM) - a sheltered workshop - was actively involved in the project. CVJM employs 380 employees with intellectual disabilities and over 70 specialized staff. To explore the user perspective, employees with intellectual disabilities as well as the production supervisor, the factory supervisor and three team leaders voluntarily took part in the participative research process. The team leaders selected the participating employees. In doing so, they considered those employees who have experience with the machinery and are interested in broadening their tasks. Selection criteria also ensured that the chosen employees varied in their skill levels (e.g., literacy, numerical reasoning skills, logical thinking). The team leaders talked to the employees they had in mind individually and asked them if they were interested in taking part in the research process. Six employees were selected at the end. They gave their consent that the data and information they contribute within the research process could be used for the project. The employees were considered and treated as experts or consultants because they work at the machines and experience the barriers in operating them on a daily basis. The team leaders were always present during the research process and before each research phase the team leaders prepared their employees on what they might expect. Table 1 provides socio-demographic information about the employees with intellectual disabilities who took part in the research process.

Tab 1 Socio-demographic data of the participating employees with intellectual disabilities

\begin{tabular}{|l|l|l|l|}
\hline Sex & Age & $\begin{array}{l}\text { Has held current position } \\
\text { since: }\end{array}$ & Shop-floor level \\
\hline Female & 30 years & No information & Metal processing \\
\hline Male & 45 years & 10 years & Metal processing \\
\hline Male & 32 years & 3 years & Carpentry \\
\hline Male & 61 years & No information & Carpentry \\
\hline Male & 47 years & 2 years & Large-scale catering \\
\hline Male & 48 years & 10 years & Large-scale catering \\
\hline
\end{tabular}

\subsubsection{Expert interviews}

We started the requirement analysis by conducting semi-structured guided interviews with the specialized staff and the employees and by observing the users' activities in order to gain knowledge of the users and their working tasks, the working procedures, working context, and business processes (see Wiesner-Steiner et al. 2014). The interviews and observations took place in the rooms and shopfloors of CVJM - in the familiar environment of the participants - and lasted half an hour to one hour. 
The interviews with the production supervisor, the factory supervisor and three team leaders, one each from the shop-floor levels of metal processing, carpentry and large-scale catering, were conducted individually. Two employees with intellectual disabilities from each of these shop-floor levels were interviewed together and in the presence of the corresponding team leader to build-up a trust-based relationship. This was essential for the well-being of the employees because the interviews, observations and workshops were unfamiliar situations for them. The questions and the observations focused on the current work on the machines, the interaction with them and the use of technology in general. The topics of the interviews are listed in table 2. Within the observations the employees demonstrated how the machines they are working at function and which products they produce. The team leaders indicated which control and support functions they installed by themselves such as masking unnecessary buttons that otherwise would irritate the employees. They also showed functions whose operation is to date too complicated and that can therefore only be carried out by specialized staff. The interviews and observations allowed specific insights into the perception of the day-to-day work, the used machines and the corresponding interaction of employees with intellectual disabilities with complex machines. Furthermore, the organizational conditions under which the humantechnology interaction (HTI) takes place in sheltered workshops could be examined.

Tab 2 Applied research methods

\begin{tabular}{|c|c|c|c|}
\hline Research method & Central questions & Objectives & Evaluation \\
\hline Interviews & $\begin{array}{l}\text { - Personal and activity } \\
\text { - details } \\
\text { - Use of technology } \\
\text { - Skills and impairments } \\
\text { of the employees } \\
\text { - Organization of work } \\
\text { - Product range } \\
\text { - Type of machines } \\
\text { - Work on and use of } \\
\text { - Probhines } \\
\text { - Heachines in operating } \\
\text { - Support functions }\end{array}$ & $\begin{array}{l}\text { - Assessment of the status } \\
\text { quo } \\
\text { - Exploring the field of } \\
\text { investigation }\end{array}$ & - Content analysis \\
\hline Observations & $\begin{array}{l}\text { - Operation of machines } \\
\text { - Health and safety control } \\
\text { - Support functions } \\
\text { - Problems in operating } \\
\text { machines }\end{array}$ & $\begin{array}{l}\text { - Assessment of the status } \\
\text { quo } \\
\text { - Exploring the field of } \\
\text { investigation }\end{array}$ & $\begin{array}{l}\text { - Video analysis } \\
\text { - Analysis of the protocols } \\
\text { of observation }\end{array}$ \\
\hline $\begin{array}{l}\text { Workshop1: Creativity } \\
\text { Laboratory }\end{array}$ & $\begin{array}{l}\text { - Requests regarding the } \\
\text { work on machines } \\
\text { - Ideas regarding the work } \\
\text { on machines }\end{array}$ & $\begin{array}{l}\text { - Identification of the user } \\
\text { perspective }\end{array}$ & $\begin{array}{l}\text { - Analysis of the records of } \\
\text { the workshop (protocol, } \\
\text { video, audio, and image } \\
\text { recording, developed } \\
\text { machines and control } \\
\text { panels) }\end{array}$ \\
\hline $\begin{array}{l}\text { Workshop 2: Tablet } \\
\text { Usability Test }\end{array}$ & $\begin{array}{l}\text { - } \text { Needs } \\
\text { - Skills } \\
\text { - } \text { Preferences } \\
\text { - } \text { Impairments } \\
\text { Requirements }\end{array}$ & $\begin{array}{l}\text { - Identification of the user } \\
\text { perspective }\end{array}$ & $\begin{array}{l}\text { - Analysis of the records of } \\
\text { the workshop (protocol, } \\
\text { video, audio and, image } \\
\text { recording) } \\
\text { - Log file analysis }\end{array}$ \\
\hline
\end{tabular}




\begin{tabular}{|l|l|l|l|}
\hline $\begin{array}{l}\text { Workshop 3: Design } \\
\text { Thinking }\end{array}$ & $\begin{array}{l}\text { - Typical user } \\
\text { Typical working } \\
\text { situation }\end{array}$ & Prototyping and testing & $\begin{array}{l}\text { - Analysis of the records of } \\
\text { the workshop (protocol, } \\
\text { video, audio, and image } \\
\text { recording, developed } \\
\text { control panels) }\end{array}$ \\
$\begin{array}{l}\text { Interpretation of the } \\
\text { results by external } \\
\text { experts } \\
\text { Test of the final } \\
\text { prototype by users }\end{array}$ \\
\hline
\end{tabular}

\subsubsection{Workshops}

In the researchers' opinion, the complexity of the iBaMs project lies, amongst other things, in accurately exploring the wishes and needs of the employees. Therefore, after the interviews and observations, three different kinds of workshops were developed and conducted that aimed at facilitating the expression of wishes, requirements, needs and preferences through speaking, painting, doing handicraft work, testing etc. In the first workshop, called "Creativity Laboratory", ideas were gathered about how a control panel could be designed, and which elements it should have to make the operation of complex computer-controlled machines simpler for users with intellectual disabilities. Participants of this workshop were (once again) the six employees with intellectual disabilities and their three team leaders. The latter occupied a dual role: on one hand, they accompanied the employees and, on the other hand, they developed ideas by themselves. Various methods were applied in order to generate new and maybe unconventional ideas: Starting with a brainstorming phase that addressed questions such as "What works well regarding the work on machines? What is missing? What acts as a barrier to using the machine? Which problems exist?". This was followed by a comprehensive idea generation phase in which imaginary machines and control panels were built with common handcrafted materials. In this manner, ideas and concepts could be developed that are not easily formulated and thought of and that therefore are not generated with methods like group discussions, interviews or questionnaires. In addition, these creative methods could be designed in such a way that they were accessible to employees with intellectual disabilities.

For the second workshop, called "Tablet Usability Test", five specific applications (apps) were programmed with varying levels of difficulty to test preferences and abilities for the use of digital technology. Care was taken that the programmed apps were accessible to the employees with intellectual disabilities. It is for this reason that existing apps could not be used and new ones, especially designed for this workshop, were programmed. For example, instructions should be provided in other formats than writing because of poor reading skills. The six employees and their three team leaders as companions and supporters in conducting the exercises participated in this workshop. Within one app, for example, the participants were asked to choose a color or shape for the start and another one for the stop button. Afterwards, the users were invited to press the start button and to wait until a simulated working process (visualized by black vertical lines that successively become green) was finished. Only then were they allowed to press the stop button. By performing only 
this app, various preferences and skills could be investigated: preferences for colors and shapes, motor skills or in this case dexterity as the preferred color/shape had to be dragged to the start/stop button by the finger, and patience. The choices and the actions were logged in the background of the app. It was recorded how often the dragging failed (dexterity) and if the stop button was pressed on time (patience) as well as if instructions were followed. Moreover, it was examined if it is useful and desirable to have different support functions: Thus, a voice guided the participants through this exercise. There also was the opportunity to watch a video tutorial how to perform the app. Smileys were used to help mark the start and stop button as well as to indicate if the exercise was successfully completed. Log files that tracked the users' actions facilitated the evaluation of the app exercises.

The objective of the third workshop, called "Design Thinking" (Plattner et al. 2009), was to reflect the results of the previous workshops, define the design specifications for an assistive control panel and, using handcrafted materials, to develop prototypes of a control panel that caters to the users' requirements and skills. The Design Thinking workshop consisted of two parts: prototype development with handcrafted materials and testing. Participants of the first part of the workshop were specialized staff of CVJM - the three team leaders, supervisors, the manager-, external experts and the iBaMs project team (in total 19 participants). At the beginning of the Design Thinking workshop all participants were made acquainted with the insights received from the interviews, the observations and the previous workshops. The participants were then separated into two groups and each group created a picture of a typical female or male user of the control panel to be developed with different personality traits, cognitive skills, impairments and needs. In a brainstorming session afterwards, the attendees looked for answers to the question "How can we imagine the typical female and male user in a working situation?". Teams of two people subsequently developed seven prototypes with handcrafted materials based on the brainstorming result. At the end of the first part, all participants evaluated all prototypes in order to identify the best elements for the final prototype. The final prototype is shown in figure 2. On the left hand side Anne is signed in as a user. Her display interface indicates the machine and the working process of which she has already completed the first three steps. She uses four keys to operate the machine. On the right hand side Boris is signed in as a user. His display interface shows an error message (red display). It indicates at which point in the machine the problem exists. He uses two keys to operate the machine. 


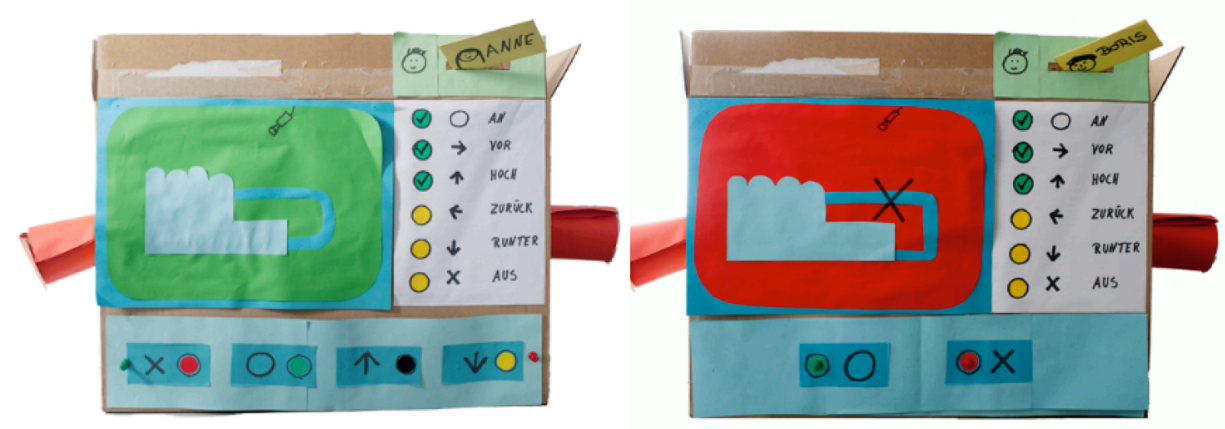

Fig 2 Final handcrafted prototype of the project iBaMs

The second part of the Design Thinking workshop "testing" was carried out in a separate event to which, besides the three team leaders, the six employees with intellectual disabilities were invited as users to simulate the use of the final handcrafted prototype. The team leaders instructed their employees in operating the control panel prototype as it would be in real working life. The questions and experiences of the employees and team leaders alike with the control panel prototype form the first basis, which still has to be broadened in further research activities (see section 6), for the technological development that should be realized in a follow-up project.

\subsection{Matching}

\subsubsection{General aim}

In this section the mathematical approach concerning the fourth research question is described. The procedure was based on the following:

- Discussions with the user group, for example, employees of CVJM, etc.; the results are personal opinions, i.e. they are subjective.

- The procedure of defining indicators aims at abstracting from these subjectivities.

- Partial orders are applied to optimal profiles.

- Finally, the best combination is found.

Only the two main steps of the matching procedure are described in the two subsequent sections, as the matching procedure is only a single aspect of the whole paper and only fictitious data was used (for technical details, see Bruggemann et al. 2017). The aim was to identify control panels appropriate to the employees' requirements and skills which are in line with potential economic or technical restrictions. In contrast to the first three questions, a concept was developed which

- abstracts as far as possible from personal findings (related to the six employees) and

- is flexible enough to meet the above mentioned constraints and the inherent social complexity.

\subsubsection{Determination of optimal user and control panel profiles (first step)}

a) Indicators for the control panels (CP) of the machines and for user profiles (UP) of the employees are defined.

b) Deriving from item a) two multi-indicator systems are obtained. 
c) Since the problem involves multiple criteria and it is therefore not possible to determine a unique simple ordering with one best solution, the optimization is performed by partial order methodology (Bruggemann and Patil 2011; Bruggemann et al. 2017). As two sets of indicators are considered, the partial order methodology was applied for each single set of indicators separately. A graph (in technical terms a Hasse diagram) is obtained for each set, see for example figure 3 with fictitious data for demonstration.

d) The list of optimal UPs and CPs is extracted from each graph. The results can be seen in figure 3 which has $\mathrm{UP}_{1}, \mathrm{UP}_{2}, \mathrm{UP}_{3}$ on the one side and $\mathrm{CP}_{1}, \mathrm{CP}_{2}, \mathrm{CP}_{3}, \mathrm{CP}_{4}$ on the other side (for technical details, see Bruggemann and Patil 2011; Bruggemann et al. 2017).
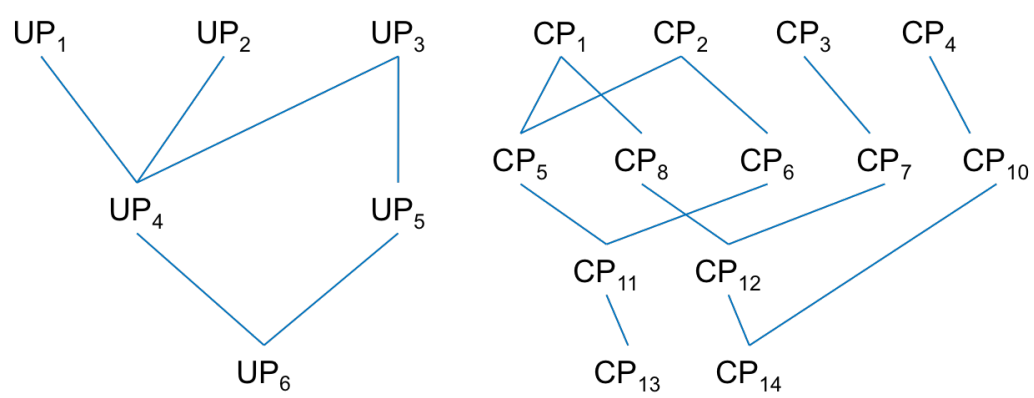

Fig 3 Fictitious Hasse diagrams of six user profiles (UP) and fourteen control panels (CP). Maximal elements among user profiles: $\mathrm{UP}_{1}, \mathrm{UP}_{2}, \mathrm{UP}_{3}$; maximal elements among the control panels: $\mathrm{CP}_{1}, \mathrm{CP}_{2}, \mathrm{CP}_{3}, \mathrm{CP}_{4}$.

\subsubsection{Matching procedure (second step)}

Because each CP can be assigned in principle to any UP, the plurality of data and the complexity of the iBaMs project leads to $\mathrm{r} \times \mathrm{n}$ possible assignments, given $\mathrm{r}$ user profiles (UP) and $\mathrm{n}$ control panels (CP) (see figure 4 assuming $r=3$ and $n=4$ ).

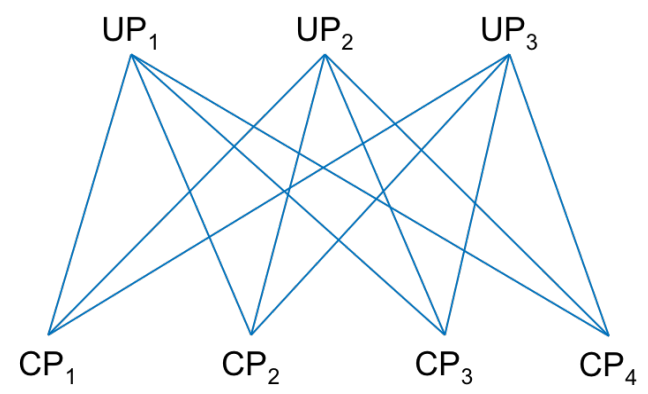

Fig 4 Visualization of all possible assignments with three user profiles (UP) and four control panels (CP)

The matching procedure has to evaluate each combination of user profile and control panel. The second step again needs two sub-steps: (i) Which single user indicator can be associated with which single indicator of the control panel? For example, can an indicator describing the optical ability of an employee be combined with the haptic facility of the control panel in a meaningful manner? To answer this question, this sub-step needs a mathematical formulation by a matrix $\mathrm{M}$ which itself is based on expert knowledge (details, see Bruggemann et al. 2017). 
(ii) Since this is a multiple-criteria optimization problem, there is - a priori-not a unique solution. The optimization (i.e. which UPs combines best with which CPs) can be performed using the heuristic Copeland method (see, for example, Al-Sharrah 2010). The multi-criteria decision support method of Copeland is a very simple outranking method, based on the mutual comparison of indicator values for each pair of objects. There are several variants possible (for details see Al-Sharrah 2010). By means of the Copeland method, a pair of indicator values (one taken from the set of UPs and one taken from the set of CPs) is tested and compared with any other pair $\left(\mathrm{UP}_{\mathrm{i}}, \mathrm{CP}_{\mathrm{j}^{\prime}}\right),(\mathrm{i}=\mathrm{i}$ ' and $\mathrm{j}=\mathrm{j}$ ' excluded $)$ and a value for the Copeland index is obtained. Through the Copeland index all the combinations among the optimal CPs and UPs can be ordered and some combinations of user profile and control panels turn out to be favorable (see figure 5). By the Copeland method a sequence of UPs and CPs is obtained and for example the three best pairs are selected which are $\left(\mathrm{UP}_{1}, \mathrm{CP}_{4}\right),\left(\mathrm{UP}_{2}, \mathrm{CP}_{1}\right),\left(\mathrm{UP}_{3}, \mathrm{CP}_{4}\right)$. These pairs are visualized in figure 5, i.e. each pair is visualized by two vertices which are connected by a line.

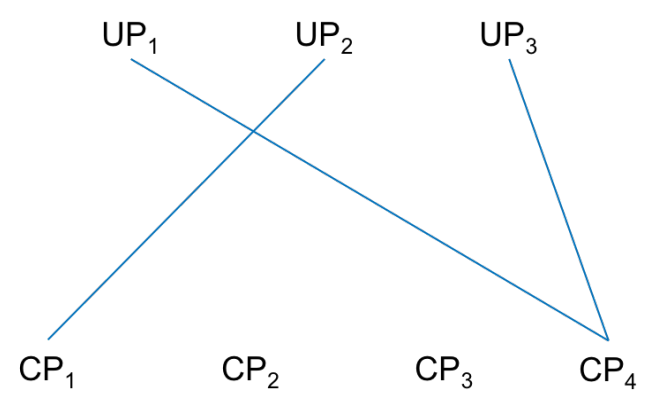

Fig 5 Model solution of the matching process with three user profiles (UP) and four control panels (CP). From all UP, CP combinations (as visualized in figure 4) the three best ones (due to the Copeland index) were selected. These three pairs are $\left(\mathrm{UP}_{1}, \mathrm{CP}_{4}\right),\left(\mathrm{UP}_{2}, \mathrm{CP}_{1}\right)$ and $\left(\mathrm{UP}_{3}, \mathrm{CP}_{4}\right)$, where $\mathrm{UP}_{\mathrm{i}}$ and $\mathrm{CP}_{\mathrm{j}}$ ("vertices") are connected by a line.

\section{Results}

4.1 Requirements for an assistive accessible control panel

It was established that the employees involved in the participative research process have experience with the machinery of the shop-floor levels metal processing, carpentry, and large-scale catering. Their current range of tasks includes loading machines with material and correcting errors. The current barriers in operating these machines are setting them up, starting them, and controlling them. The employees interviewed for the project also use digital technology in their spare time, such as computers, cell phones, or game consoles. But they are not familiar with new communication and information technologies like portable PCs, tablets, or smartphones.

The key finding of iBaMs is that employees with intellectual disabilities have a wide range of abilities, needs, preferences, impairments, etc. In addition, the components of the user profiles are to a high degree variable. They depend, for example, on the daily form or mood of the employee. In line with the research findings of Mazzone et al. (2010), this fact requires a high level of flexibility and adaptability in the control panel. There are highly individual abilities and requirements; nevertheless there are some common characteristics. Thus, the employees involved in the research process show a high level of motivation, enjoyment of work, a strong sense of duty, a positive work attitude, and low 
levels of absenteeism. However, we have learned that most of the employees also have physical impairments, that they have problems in reading and writing, deficiencies in numerical comprehension, and some of them cannot assess the results of their actions. All these barriers need to be considered in the development of a control panel that can support people with intellectual disabilities to take on more responsibility and perform more demanding tasks on complex computercontrolled machines.

To achieve the required flexibility and adaptability, a key design demand is the personalization of the display interface by means of a modular design that comprises different elements for instructions, support, error messages, information on solutions, different kinds of keys and knobs (press, turning, control lever), etc. The configuration system must be designed in such a way that the specialized staff - people without programming expertise - can easily adapt the display interface to a particular user. The team leader must be able to adjust the necessary elements on and around the display interface individually out of a large database with media, software, and hardware components.

Like Irwin and Sesto (2012), it was also observed that the participants pressed the touch-screen interface harder and longer than necessary. For that reason and to inform the employee that an operation has been activated, it is necessary that the control panel give tactile, audio or visual feedback when the touch screen or a button has been pressed. In the intended follow-up project, in which a real and functioning prototype of the assistive accessible control panel should be developed (see figure 1), the preferences of employees with intellectual disabilities regarding the kind of feedback should be investigated.

We also discovered the central role team leaders play. They are, for example, important in helping the employees gain confidence and the belief that they can operate machines. Hence, the introduction of a control panel as assistive learning technology cannot take place without an intensive introduction and direction from the team leaders. Moreover, learning units and working steps should be kept short and simple and need continuous repetition and permanent guidance throughout the working process. These findings are reflected in the desire expressed by the employees for interaction with the control panel and the team leader. In addition, they would like support in different forms - for example, a video tutorial that shows what happens if a button is pressed or how the next step is carried out. Because it takes time for the employees to familiarize themselves with new circumstances, equipment and processes, and also because learning units should be kept short and simple, the introduction of control panels will lead to a heavier workload for the team leaders at the beginning but should in the end reduce the amount they have to do.

In the context of sheltered workshops and elsewhere, there are restrictions to the level of automation that can be achieved. Thus, care must be taken to ensure that the control panel allows the employees scope for decision-making and action and that it serves as a support and qualification tool. 


\subsection{Indicators for future matching}

The wide range of changeable abilities and preferences of employees with intellectual disabilities and the flexible and adaptable features required in the control panel lead to the complex issue facing iBaMs, namely, discovering which display interface best suits a given user profile. Based on the requirement analysis, the following social indicators (see table 3) describing possible impairments, abilities as well as preferences were identified as relevant factors in characterizing the user profiles of employees with intellectual disabilities for using digital technology.

Tab 3 Possible social indicators for the characterization of user profiles

\begin{tabular}{|c|c|}
\hline \multirow[t]{5}{*}{ Impairments } & Hearing \\
\hline & Seeing \\
\hline & Speaking \\
\hline & Tactile sense \\
\hline & Motor skills and dexterity \\
\hline \multirow[t]{10}{*}{ Abilities } & Verbal skills \\
\hline & Literacy \\
\hline & Numerical reasoning skills \\
\hline & $\begin{array}{l}\text { Powers of comprehension (i.e. how well does the employee understand explanations } \\
\text { and instructions) }\end{array}$ \\
\hline & Reason (i.e. logical thinking, ability to assess consequences) \\
\hline & Ability to concentrate \\
\hline & Memory retention \\
\hline & $\begin{array}{l}\text { Ability to deal with complexity (for example, what is the maximal amount of } \\
\text { information on a control panel that can be perceived and processed) }\end{array}$ \\
\hline & Learning aptitude and motivation \\
\hline & Autonomy \\
\hline \multirow[t]{4}{*}{ Preferences } & Preferences for and recognition of colours \\
\hline & Preferences for and understanding of icons \\
\hline & Preferences for types of support (audio, video, etc.) \\
\hline & Preferences for and familiarity with different types of media \\
\hline
\end{tabular}

As can be seen from the kind of indicators listed, the values of most of them can be linguistically rated as good, mediocre, or poor.

Because of the limited time span of one year, it was not possible to develop a real prototype of an assistive accessible control panel for employees with intellectual disabilities in iBaMs. Therefore, the following indicators of an assistive control panel (see table 4) should be regarded as a first approach that needs to be extended and evaluated in the intended follow-up project. 
Tab 4 Possible technical indicators for the characterization of control panels

\begin{tabular}{|l|l|}
\hline \multirow{5}{*}{ Accessibility } & Requirement for spoken and written explanations \\
\cline { 2 - 3 } & Requirement for understanding numbers \\
\cline { 2 - 3 } & Operation possibilities (with one hand, two fingers, etc.) \\
\cline { 2 - 2 } & Display brightness \\
\cline { 2 - 3 } & Magnification \\
\hline \multirow{5}{*}{ Usability } & Number of features \\
\cline { 2 - 3 } & Self-explanatory functions \\
\cline { 2 - 3 } & Personalization \\
\cline { 2 - 3 } & Ergonomics \\
\cline { 2 - 3 } & Cost effectiveness \\
\hline \multirow{5}{*}{$\begin{array}{l}\text { Interaction possibilities with the control panel (image and speech recognition) or } \\
\text { with another person (e.g., specialized staff) }\end{array}$} \\
\cline { 2 - 3 } & Support or enabling of learning processes \\
\cline { 2 - 3 } & Type of visible support (audio, video, icons, etc.) \\
\cline { 2 - 3 } & Invisible support and control \\
\cline { 2 - 3 } & Working process guidance \\
\hline
\end{tabular}

The concept developed for the matching process (see section 3.2) was tested using fictitious control panels and user profiles. This could be used to demonstrate the general applicability of the concept of matching methodology for the selection of an optimal control panel, with due attention paid to its cost effectiveness and other not immediately foreseen restrictions.

\section{Conclusions}

To conclude, and to answer the question raised in the title, the empowerment of employees with intellectual disabilities could be supported by the development of an assistive accessible control panel (specified in section 4.1). This control panel should be personalized to the requirements and the mental state of each employee. The mental state of the employee can change on a daily base. Thus, it could be the case that an employee needs more guidance and support on one day and less on another day. On one hand, this is an issue of complexity, and on the other hand, it is a factor that requires high flexible optimization tools as described in 3.2. The empowerment process can be further supported by the use of social and technical indicators that allow the optimal control panel to be matched to given users, including their requirements and capacities. From the researchers' point of view, the matching process and all its input indicators is what is seen as a main complexity in the research field. However, further research is needed to validate the results pertaining to the user perspective and to develop the specified prototype of an assistive accessible control panel.

The iBaMs project has shown that people with intellectual disabilities are able and motivated to use digital technology to expand their range of tasks and responsibilities in working life. Furthermore, the concept of matching methodology was successfully applied to solving the complex problem of assigning an optimal control panel to a given user profile. This enables the development of a control 
panel that does not depend on the subjectivity of the user group in the project but rather creates a generalized basis.

iBaMs also has sociopolitical implications: it has been shown that innovative technology can help to support people with intellectual disabilities in working life. Through its use, some of the barriers experienced by employees with intellectual disabilities can be overcome. The researchers' vision is that the development of an assistive accessible control panel helps to change and overcome attitudes, stereotypes and prejudices against employing people with intellectual disabilities and that it contributes to regarding them as valuable employees. Although the target users in the iBaMs research project were employees with intellectual disabilities, it is important to bear in mind that the real challenge for the future lies in creating working conditions that maintain and enhance the abilities of all employees. The concept of an assistive control panel whose display interface can be tailor-made to individual needs and skills is one possible solution that will support employees on an individual basis.

This is in line with the design for all concept that aims at designing products and services accessible to everyone. Important requirements for the development of the assistive accessible control panel are ease of use, clear navigation, avoidance of confusion and frustration through an excessive supply of features and information, different types of feedback functions, comprehensible instructions and guidance through the working process also for people with limited literacy, mathematical skills or memory retention, as well as health and safety control. These requirements are in accordance to the usability and accessibility demands of the design for all concept. The flexibility of the assistive accessible control panel by personalizing the display interface corresponds to the key criterion adjustment to individual requirements of the design for all concept. The technique of partial order as well as the matching process guarantee a high degree of flexibility to find best combinations under any additional exogenous constraints such as individual requirements.

\section{Limitations and Future Developments}

There are some limitations of the presented research project that should be addressed in future research work. The statistical basis of only six employees with intellectual disabilities in the participative research process does not allow the findings to be generalized. In a statistical sense the six people cannot be treated as a random sample representing a larger set. Furthermore, only three shop-floors in one organization were considered. The information base is too limited to generalize to a wider population. A sound empirical basis is needed in order to be able to provide evidence that the important social indicators to describe user profiles and the essential technical indicators to characterize control panels are found: further case studies within other sheltered workshops and inclusive companies alike, within other shop-floors and with other machinery have to be carried out. In order to broaden the statistical basis, there are plans to conduct the workshops "Creativity Laboratory" and "Tablet Usability Test" in other organizations employing people with intellectual 
disabilities in the follow-up project. In this way, results pertaining to the user perspective can be validated for a larger user group and with regard to other circumstances.

In addition, the independence and the (ordinal) quantification of the identified social and technical indicators as well as their ability to order the user profiles and the control panels must still be checked. Furthermore, more information about economic conditions and other (often exogenous) restrictions are needed in order to adequately describe the reality by the social and technical indicators.

The presence of the team leaders in the interviews and the workshops with the employees was seen as positive as it facilitates the establishment of trust between the researchers and employees. Nevertheless, through their presence the team leaders also influenced the research outcomes. For example, they also expressed their opinions and it could be possible that employees felt inhibited to speak freely because of the presence of their team leaders. The researchers, however, did not have that impression, they perceived that the team leaders encouraged their employees to contribute to the discussion and to express their opinions. Nevertheless, in the follow-up project it is planned to conduct workshops without the team leaders, once mutual trust is set up, in order to explore the influence of the presence of the team leaders.

In the intended follow-up project, in which a real and functioning prototype of an assistive accessible control panel is to be developed, the matching process described above should be applied to select the optimal prototype concept. Instead of using Copeland's index alternative, more flexible and sophisticated multidimensional optimization methods such as e.g. PROMETHEE (Brans and Vincke 1985; Brans et al. 1986) should be adapted to the specific needs of the integration of employees, too.

\section{References}

Agovino, M. \& Parodi, G. (2014). Identifying the Quality of Work by Fuzzy Sets Theory: A

Comparison Between Disabled and Non-disabled Workers. Social Indicators Research, 119(3), $1627-1648$.

Al-Sharrah, G. (2010). Ranking Using the Copeland Score: A Comparison with the Hasse Diagram. Journal of Chemical Information and Modeling, 50(5), 785-791.

American Association on Intellectual and Developmental Disabilities (aaidd) (2013). Definition of Intellectual Disability. http://aaidd.org/intellectual-disability/definition\#.V8QmCrXg6PI. Accessed August 29, 2016.

Angkananon, K., Wald, M. \& Gilbert, L. (2014). Applying Technology Enhanced Interaction Framework to Accessible Mobile Learning. Procedia Computer Science, 27, 261-270.

Annoni, P., Bruggemann, R. \& Carlsen, L. (2014). A Multidimensional View on Poverty in the European Union by Partial Order Theory. Journal of Applied Statistics, 42(3), 535-554. 
Annoni, P., Fattore, M. \& Bruggemann, R. (2011). A Multi-Criteria Fuzzy Approach for Analyzing Poverty Structure. Statistica \& Applicazioni, Special Issue, 7-30.

BAG WfbM (2007). Workshops. http://www.bagwfbm.eu/page/workshops. Accessed November 2, 2015.

Bergold, J. \& Thomas, S. (2012). Participatory Research Methods: A Methodological Approach in Motion. Forum: Qualitative Social Research. http://www.qualitativeresearch.net/index.php/fqs/article/view/1801/3334. Accessed November 2, 2015.

Brans, J. P. \& Vincke. P. H. (1985). A Preference Ranking Organisation Method (The PROMETHEE Method for Multiple Criteria Decision-Making). Management Science, 31(6), 647-656.

Brans, J. P., Vincke, P. H. \& Mareschal, B. (1986). How to Select and How to Rank Projects: The PROMETHEE Method. European Journal of Operational Research, 24(2), 228-238.

Bruggemann, R. \& Patil, G. P. (2011). Ranking and Prioritization for Multi-indicator Systems: Introduction to Partial Order Applications. New York: Springer.

Bruggemann, R., Koppatz, P., Fuhrmann, F. \& Scholl. M. (2017). A Matching Problem, Partial Order, and an Analysis Applying the Copeland Index. In M. Fattore \& R. Bruggemann (eds.), Partial Order Concepts in Applied Sciences (231-238). Cham: Springer.

Boccuzzo, G. \& Fabbris, L. (2012). How Do the Disabled Graduates Achieve and Spend their Human Capital Gained at University?. In: L. Fabbris (ed.), Indicators of University Education Effectiveness (105-118). Milano: McGraw-Hill.

Boccuzzo, G. \& Maron, L. (2014). Understanding Equity in Work Through Job Quality: A Comparative Analysis Between Disabled and Non-disabled Graduates Using a New Composite Indicator. In M. Carpita, E. Brentari \& Q. El Mostafa (eds.), Advances in Latent Variables: Methods, Models and Applications (263-275). Cham, Heidelberg, New York, Dordrecht, London: Springer International Publishing Switzerland.

Fattore, M. (2008). Hasse Diagrams, Poset Theory and Fuzzy Poverty Measures. Rivista Internazionale di Scienze Sociali, 116(1), 63-75.

Giannoulis, N., Kagia, A., Kakoulidis, P., Rikkou, C. \& Skourlas, Ch. (2013). Personalized Adaptive Networked Learning for Disabled Students \& Social Networking for the Inclusion of Students: The Multimedu Tool. Procedia - Social and Behavioral Sciences, 73(February), 451-455.

Graham, L. \& Ross, E. (2016). Disparities in Quality of Life Among South Africans With and Without Disabilities. Social Indicators Research, 127(2), 721-739.

Hersh, M. (2014). Evaluation Framework for ICT-based Learning Technologies for Disabled People. Computers \& Education, 78(September), 30-47. 
Hersh, M. A. \& Johnson, M. A. (2008). On Modelling Assistive Technology Systems - Part I: Modelling Framework. Technology and Disability, 20(3), 193-215.

Irwin, C. B. \& Sesto, M. E. (2012). Performance and Touch Characteristics of Disabled and Nondisabled Participants during a Reciprocal Tapping Task Using Touch Screen Technology. Applied Ergonomics, 43(6), 1038-1043.

Kim, H.-J. (2004). Persönlichkeit und Arbeit mit neuen Technologien in Werkstätten für Behinderte. Arbeitsplätze mit CNC-Technik im Vergleich zu Arbeitsplätzen mit konventionellen Maschinen. Dissertation Universität Dortmund. http://hdl.handle.net/2003/2919. Accessed December 15, 2015.

Maggino, F. (2014). The Good Society: Defining and Measuring Wellbeing, between Complexity and Limits. Journal de Ciencias Sociales, 1(1), 20-36.

Martins, A. C. (2015). Using the International Classification of Functioning, Disability and Health (ICF) to Address Facilitators and Barriers to Participation at Work. Work, 50(4), 585-593.

Mazzone, E., Gutiérrez, E., Barrera, C., Finat, C., Santos, O. C., Boticario, J. G., Moranchel, J., Roldán, J. R. \& Casas, R. (2010). Involving Users in the Design of ICT Aimed to Improve Education, Work, and Leisure for Users with Intellectual Disabilities. Computers Helping People with Special Needs, 6180, 5-12.

Plattner, H., Meinel, C. \& Weinberg, U. (2009). Design-Thinking. Munich: Mi-Fachverlag.

Revermann, Ch. \& Gerlinger, K. (2009). Technologies in the Context of Disability Compensation at the Workplace: Summary. Berlin: Office of Technology Assessment at the German Bundestag.

Seale J., Georgeson J., Mamas C. \& Swain J. (2015). Not the Right Kind of "Digital Capital”? An Examination of the Complex Relationship between Disabled Students, their Technologies and Higher Education Institutions. Computers \& Education, 82(March), 118-128.

United Nations (UN), General Assembly (2006). Final Report of the Ad Hoc Committee on a Comprehensive and Integral International Convention on the Protection and Promotion of the Rights and Dignity of Persons with Disabilities. A/61/611. https://www.usaid.gov/sites/default/files/documents/1868/discrpd.pdf. Accessed November 4, 2015.

van Campen, C. \& van Santvoort, M. (2013). Explaining Low Subjective Well-Being of Persons with Disabilities in Europe: The Impact of Disability, Personal Resources, Participation and SocioEconomic Status. Social Indicators Research, 111(3), 839-854.

Wiesner-Steiner A., Teske, A., Fuhrmann, F. \& Scholl, M. (2014). Preconditions and Design Requirements for Touch-Screen Control Panels for Intellectually Disabled Persons Working with CNC-Machines. Proceedings of the International Conferences Interfaces and Human Computer Interaction, 54-61. 
Young, I. M. (1990). Justice and the Politics of Difference. Princeton: Princeton University Press. 